\title{
EBNA-2-Deleted Epstein-Barr Virus from P3HR-1 Can Infect Rabbits with Lower Efficiency than Prototype Epstein-Barr Virus from B95-8
}

\author{
Hitoshi Sano ${ }^{a, b}$ Keiko Nagata ${ }^{a}$ Kaoru Kato ${ }^{a, c}$ Kyousuke Kanai ${ }^{a, d} K_{\text {Kiyoshige Yamamoto }}{ }^{a}$ \\ Keisuke Okuno ${ }^{a, b}$ Satoshi Kuwamoto ${ }^{a}$ Hiromi Higaki-Mori ${ }^{a}$ Hirotsugu Sugihara $^{a}$ \\ Masako Kato $^{\mathrm{a}}$ Ichiro Murakami ${ }^{\mathrm{a}}$ Susumu Kanzaki ${ }^{\mathrm{b}}$ Kazuhiko Hayashi ${ }^{\mathrm{a}}$ \\ Divisions of a Molecular Pathology and bediatrics and Perinatology, Faculty of Medicine, Tottori University, and \\ 'Kato Animal Hospital, Tottori, and d Department of Virology I, National Institute of Infectious Diseases, \\ Tokyo, Japan
}

\section{Key Words}

Epstein-Barr virus - Infection - Animal model • Rabbit •

P3HR-1 • B95-8

\begin{abstract}
Objectives: To clarify characteristics on rabbit in vivo infection with type 2 EBV nuclear antigen (EBNA-2)-deleted Epstein-Barr virus (P3HR-1-EBV) and compare infectious efficacy of P3HR-1-EBV with previously reported prototype type 1 EBV from B95-8. Methods: Twelve Japanese White rabbits were inoculated with P3HR-1-EBV via intranasal or intravenous routes and autopsied on day 70-84. Results: In only 2 of 12 P3HR-1-EBV-inoculated rabbits, EBV-DNA was detected in peripheral blood mononuclear cells (PBMCs). BamHI M rightward reading frame (BMRF)-1, EBNA-1 and BamHI Z leftward reading frame (BZLF)-1-mRNA were intermittently expressed in PBMCs. In 1 infected rabbit with continuous detection of EBV-DNA in PBMCs, many EBER-1-positive lymphocytes were observed in germinal centers and/or marginal zones in some follicles of the appendix, and for the first time a lymphocyte with EBER-1 expression infiltrating in the squamous cell layer of the tonsils was found. The other rabbit with a transient detection of EBV-DNA in PBMCs had no EBER-1positive lymphocytes in the tissues examined. Few EBER-1-
\end{abstract}

positive lymphocytes were detected in some rabbits without detection of EBV-DNA in PBMCs. Conclusions: P3HR-1EBV showed less efficient infection in rabbits than EBV from the B95-8 cell line. However, a P3HR-1-EBV-inoculated animal model is meaningful because this is the first study of EBNA-2 function on in vivo EBV infection and it demonstrated the in vivo infectivity with lytic-type infection by EBNA-2-deleted EBV.

Copyright $\odot 2013$ S. Karger AG, Basel

\section{Introduction}

Epstein-Barr virus (EBV; human herpesvirus 4) was discovered by Epstein et al. [1]. EBV persistently infects more than $90 \%$ of adults and the infection usually remains benign throughout life. Most humans are infected during childhood through saliva. EBV crosses the mucosal epithelium and infects B cells in underlying secondary lymphoid tissues such as the tonsils and lymph nodes. EBV then hides inside the nuclei of host B cells without manifesting any symptoms. EBV-infected B cells typically remain in a latent state, protected by viral proteins that both prevent their death by apoptosis and support proliferation [2]. EBV can also lytically infect to produce infec-

\section{KARGER}

Fax +4161306 1234

E-Mail karger@karger.ch

www.karger.com (c) 2013 S. Karger AG, Basel

$0300-5526 / 13 / 0562-0114 \$ 38.00 / 0$

Accessible online at:

www.karger.com/int 
tious mononucleosis, during which numerous mature viral particles are assembled and released [3]. Fortunately, the proliferation of infected $\mathrm{B}$ cells is inhibited by a T cellmediated immune response in most immunocompetent individuals. However, EBV is occasionally capable of causing severe diseases, including EBV-associated hemophagocytic syndrome and chronic active EBV infection. $\mathrm{EBV}$ is also known to be a tumorigenic virus, which is associated with a number of malignancies related to B cells, T cells, NK cells and epithelial cells. Patients with congenital or acquired immunodeficiency are at risk of EBVassociated lymphoproliferative disorders (LPD). However, the detailed mechanisms underlying their pathogenesis remain undefined because it is difficult to investigate the dynamics of EBV in vivo. Thus, it is necessary to develop an EBV-infected animal model.

Several animal models have been described for investigating the pathogenesis of EBV. EBV infects humans and specific types of New World monkeys, including the common marmoset, cotton-top tamarin and douroucouli [4-6]. EBV does not generally infect mice. However, it can infect humanized severe combined immunodeficient mice that have undergone human hematopoietic stem cell transplant [7-10]. These animals are precious and it is difficult to use them in general laboratories because of problems with breeding, handling techniques and costs. It has been reported that rabbits can be infected with herpesvirus papio, which is a type of lymphocryptovirus that affects baboons, and that they develop herpesvirus papio-associated LPD and hemophagocytic syndrome [11-13]. Rabbits are easy to maintain and it is straightforward to collect blood from their ear veins. They are also suitable for long-term observation. We had recently reported that EBV from the B95-8 cell line (B95-8-EBV) infected rabbit lymphocytes in vivo via intravenous inoculation, which elicited a variety of host reactions [14], while some rabbits were also infected through the intranasal route [15]. We also detected EBV-DNA continuously or intermittently in peripheral blood mononuclear cells (PBMCs) throughout a lifespan of more than 1,200 days in rabbits inoculated with B95-8-EBV [16]. This demonstrated that B95-8EBV can cause transient and/or latent infections in rabbits. Thus, this rabbit model was shown to be convenient and appropriate for investigating the in vivo mechanisms of EBV infection and pathogenesis.

In this study, we inoculated 12 rabbits using EBV from the P3HR-1 cell line (P3HR-1-EBV), which lacks EBV nuclear antigen-2 (EBNA-2) and the last two exons of EBNAleader protein (EBNA-LP) [17], and quite efficiently in- fects B cell lines [18]. P3HR-1-EBV can also infect human $B$ lymphocytes in vitro, although it cannot transform them [19], meaning EBNA-2 is essential for B cell transformation [19].

Therefore, we hypothesized that there would be differences in the efficiency and pattern of EBV infection in type 2 EBV with EBNA-2 deletion (P3HR-1-EBV) and type $1 \mathrm{EBV}$ (B95-8-EBV) inoculated rabbits. We also tested the effect of type 2 EBV with ENBA-2 deletion on inoculated rabbits and compared data obtained using P3HR$1-E B V$ in the present study with that obtained using prototype B95-8-EBV-infected rabbits in previous studies.

\section{Materials and Methods}

\section{EBV-Producing Cells and Culture}

P3HR-1 cells were cultured in RPMI 1640 medium (Nissui, Tokyo, Japan) with 5\% FBS, glutamine and antibiotics (penicillin$\mathrm{G}$ and streptomycin). Cultures were incubated at $37^{\circ}$ for 1 week and then incubated at $33^{\circ}$ for 2 weeks. The supernatant obtained from the P3HR-1 culture was filtered through $0.8-\mu \mathrm{m}$ filters to remove the cells and then centrifuged at $12,000 \mathrm{~g}$ for $90 \mathrm{~min}$ to collect virions using the Compact High Speed Refrigerated Centrifuge 7780 (Kubota, Tokyo, Japan). The pellets were diluted with fresh RPMI 1640 medium and inoculated into rabbits after determining the EBV-DNA copy number by real-time polymerase chain reaction (PCR), as described later.

\section{Rabbits and Inoculation with EBV}

We obtained specific pathogen-free normal male Japanese White rabbits (weight, 2-3 kg) from Shimizu Laboratory Supplies (Kyoto, Japan). The viral solution described above was inoculated into 12 rabbits via intranasal $(n=8)$ or intravenous $(\mathrm{n}=4)$ routes. The inoculated EBV copy numbers for each rabbit were determined by real-time PCR assay (table 2). The rabbits inoculated via the intranasal route were referred to as $\mathrm{O}-23$, $\mathrm{O}-52, \mathrm{O}-122, \mathrm{O}-123, \mathrm{O}-124, \mathrm{O}-125, \mathrm{O}-206$ and O-208, while those inoculated via the intravenous route were referred to as P-203, P-205, P-207 and P-208. The day of viral inoculation was defined as 'day 0.' Unused culture RPMI 1640 medium containing 5\% FBS was inoculated into 3 rabbits via both routes as negative controls.

The animal experiments were performed under the control of a committee in accordance with the Guidelines for Animal Experimentation in the Faculty of Medicine, Tottori University, the Law Concerning the Human Care and Control of Animals (Law No. 105; October 1, 1973), and the Japanese Government Notification on Feeding and Safekeeping of Animals (Notification No. 6; March 27, 1980).

\section{Real-Time PCR of EBV-DNA}

The PCR primers selected for this assay were specific for the BALF5 gene, which encodes the viral DNA polymerase [21, 22]. Real-time PCR was performed using DNA from blood or culture supernatant using the TaqMan PCR Kit (PE Applied Biosystems), as described previously $[14,15]$. 
Table 1. Primers of EBV-related genes used in RT-PCR

\begin{tabular}{|c|c|c|}
\hline $\begin{array}{l}\text { BMRF1(EA) } \\
\text { Target size: } 246 \text { bp }\end{array}$ & $\begin{array}{l}\text { Sense } \\
\text { Antisense }\end{array}$ & 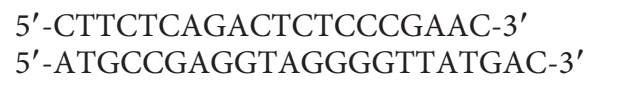 \\
\hline $\begin{array}{l}\text { EBNA1 } \\
\text { Target size: } 178 \mathrm{bp}\end{array}$ & $\begin{array}{l}\text { 1st Sense } \\
\text { 1st Antisense } \\
\text { 2nd Sense } \\
\text { 2nd Antisense }\end{array}$ & $\begin{array}{l}\text { 5'-TCTGGAGCCTGACCTGTGAT-3' } \\
\text { 5'-CTCCTCGTCCTCGTCCTCTT-3' } \\
\text { 5'-ATAGACCGCCAGTAGACCTG-3' } \\
\text { 5'-GGTTATCACCCCCTCTTCTT-3' }\end{array}$ \\
\hline $\begin{array}{l}\text { EBNA2 } \\
\text { Target size: } 279 \mathrm{bp}\end{array}$ & $\begin{array}{l}\text { 1st Sense } \\
\text { 1st Antisense } \\
\text { 2nd Sense } \\
\text { 2nd Antisense }\end{array}$ & $\begin{array}{l}\text { 5'-ACCCAGACGAGTCCGTAGAA-3' } \\
\text { 5'-CCCATGTAACGCAAGATAGA-3' } \\
\text { 5'-GGTCCTCGTCCAGCAAGAA-3' } \\
\text { 5'-ACACCACGTCACACGCCAGT-3' }\end{array}$ \\
\hline $\begin{array}{l}\text { BZLF1 } \\
\text { Target size: } 567 \text { bp }\end{array}$ & $\begin{array}{l}\text { 1st Sense } \\
\text { 1st Antisense } \\
\text { 2nd Sense } \\
\text { 2nd Antisense }\end{array}$ & $\begin{array}{l}\text { 5'-ATTGCACCTTGCCGCCACCTTTG-3' } \\
5^{\prime} \text {-CGGCATTTTCTGGAAGCCACCCGA-3' } \\
5^{\prime} \text {-GACCAAGCTACCAGAGTCTAT-3' } \\
\text { 5' -CGGCATTTTCTGGAAGCCACCCGA-3' }^{\prime}\end{array}$ \\
\hline $\begin{array}{l}\text { GAPDH } \\
\text { Target size: } 621 \mathrm{bp}\end{array}$ & $\begin{array}{l}\text { Sense } \\
\text { Antisense }\end{array}$ & $\begin{array}{l}\text { 5'-GGAGCCAAAAGGGTCATCATC-3' } \\
5^{\prime} \text {-GCTGTAGCCAAATTCGTTGTCATA-3' }\end{array}$ \\
\hline
\end{tabular}

EBV Antibody Analysis by ELISA

EBV antibodies in rabbit serum were measured by ELISA. The anti-EBV-virus capsid antigen (VCA)-IgG, EBNA-IgG and early antigen (EA)-IgG were measured by the EBV Viral Capsid-p18 (VCA-p18) Antigen IgG ELISA (Panbio, Brisbane, Qld., Australia), EBV EBNA-1 IgG ELISA (Panbio) and Epstein-Barr EA (EAD) ELISA IgG (Vircell, Granada, Spain). Each antibody was measured as described previously $[14,15]$.

RNA Extraction from PBMCs and Storage

PBMCs were collected from rabbit peripheral blood in tubes containing Cell Banker 1 (Juji Field, Tokyo, Japan) and then stored at $-80^{\circ}$ until use. RNA was extracted from PBMCs with the RNeasy Micro Kit (Qiagen, Hilden, Germany) and QIA Shredder (Qiagen), according to the manufacturer's protocol.

Detection of EBV Gene-Related mRNAs in PBMCs by RT-PCR The quantity of mRNA was determined in PBMCs using a NanoDrop system (Thermo Scientific, Wilmington, Ohio, USA) with $500 \mathrm{ng}$ of each RNA sample. RT-PCR was performed using the TaKaRa RNA PCR ${ }^{\mathrm{TM}}$ Kit (AMV) Ver. 3.0 (TaKaRa Bio., Otsu, Japan) according to the manufacturer's protocol. The mRNA expression of BamHI M rightward reading frame (BMRF)-1 (EA), EBNA-1, EBNA-2, EBV latent membrane protein (LMP)-1 and $B a m H I Z$ leftward reading frame (BZLF)-1 were investigated in PBMCs from O-23, O-52, P-205 and O-122 using PCR or nested PCR with the primers shown in table 1 [23]. The mRNA of glyceraldehyde-3-phosphate dehydrogenase (GAPDH) was analyzed as an internal control. The PCR mixture contained $2 \mu \mathrm{l}$ of $10 \mathrm{Ex}$ Taq buffer, $1.6 \mu \mathrm{l}$ of dNTP mixture, $0.1 \mu \mathrm{l}$ of dNTP mixture, 0.1 $\mu \mathrm{l}$ of TaKaRa Ex Taq HS, $12.3 \mu \mathrm{l}$ of $\mathrm{H}_{2} \mathrm{O}, 1 \mu \mathrm{l}$ of sense primer, $1 \mu \mathrm{l}$ of antisense primer and $2 \mu \mathrm{l}$ of the sample.

Pathological and Immunohistochemical Analysis

All rabbits were euthanized and autopsied 70-84 days after inoculation. Organs were examined microscopically, including the tonsils, spleen, mesenteric lymph nodes, appendix and liver. The specimens were hematoxylin-eosin (HE) stained and then immunostained with mouse monoclonal antibodies against LMP1 (clone CS1-4; DAKO, Kyoto, Japan), EBNA-2 (clone PE2; DAKO) and BamHI Z fragment Epstein-Barr Replication Activator (ZEBRA, clone BZ.1; DAKO). Immunohistochemistry and antigen retrieval was performed as described previously [14, 15].

\section{RNA in situ Hybridization}

EBV-encoded RNA (EBER)-1 expression was determined by in situ hybridization (ISH) with a fluorescein isothiocyanate (FITC)-labeled oligonucleotide probe that was complementary to the EBER-1 sequence 5'-AGACACCGTCCTCACCACCCGGGACTTGTA-3' [24]. ISH was performed as described previously [11-13] using routinely processed sections of paraffin-embedded samples of EBV-positive gastric cancer as a positive control and samples from the spleen, mesenteric lymph nodes, appendix, tonsils and liver of the autopsied rabbits. The DAKO ISH detection kit was used with the FITC-labeled DNA probes (Code No. K5201), including an AP-labeled rabbit anti-FITC antibody and 5-bromo-4-chloro-3-indolyl phosphate/nitroblue tetrazolium (BCIP/NBT).

\section{Results}

Detection of EBV-DNA in PBMCs from Rabbits

Inoculated via the Intranasal or Intravenous Routes

Table 2 provides a summary of rabbits inoculated with P3HR-1-EBV. EBV-DNA was detected in PBMCs from 2 out of 8 rabbits inoculated via the intranasal route $(\mathrm{O}-23$ and O-52). EBV-DNA was detected in O-23 from day 21 $\left(3.0 \times 10^{2}\right.$ copies $\left./ 10^{6} \mathrm{WBCs}\right)$ to day $77\left(7.3 \times 10^{2}\right.$ copies $\left./ 10^{6} \mathrm{WBCs}\right)$, while a maximum copy number of $6.0 \times$ 
Table 2. Summary of P3HR-1 EBV-inoculated rabbits used in this study

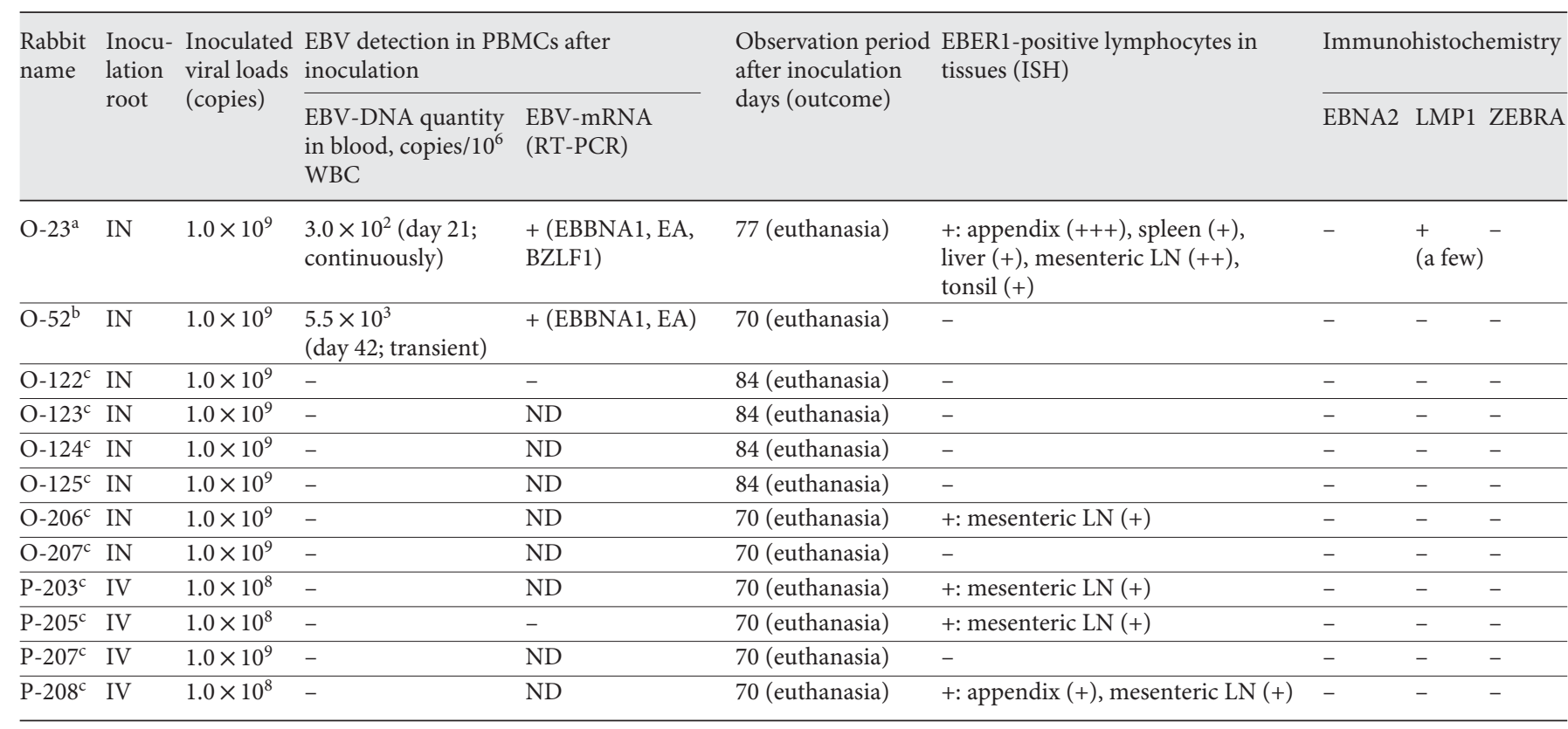

IN = Intranasal; IV = intravenous; $\mathrm{WBC}=$ white blood cells; $\mathrm{LN}=$ lymph node; $\mathrm{ND}=$ not determined; $+=$ positive; $-=$ negative. ${ }^{a}$ Continuously EBV-DNA-positive rabbit $(\mathrm{n}=1)$; ${ }^{\mathrm{b}}$ Transiently EBV-DNA-positive rabbit $(\mathrm{n}=1) ;{ }^{\mathrm{c}}$ EBV-DNA-negative rabbits $(\mathrm{n}=$ $10)$.

$10^{3}$ copies $/ 10^{6}$ WBCs was observed on day 70 (fig. 1A-1). After day 63, O-23 lost weight rapidly (from 4.3 to $4.0 \mathrm{~kg}$ within 2 weeks). EBV-DNA $\left(0.6 \times 10^{2}\right.$ copies $\left./ 10^{6} \mathrm{WBCs}\right)$ was transiently detected in O-52 on day 42 after inoculation, but not again (fig. 1B-1). EBV-DNA was not detected in PBMCs from the 4 rabbits inoculated via the intravenous route.

\section{Levels of EBV Antibodies in Rabbit Serum}

The EA-IgG levels sharply increased in O-23 from day 35 to 49 , and these high levels were subsequently maintained (fig. 1A-1). The EA-IgG levels increased transiently in $\mathrm{O}-52$ on day 14 (fig. 1B-1), although the levels did not increase in other rabbits (fig. 1C-1, d-1). The VCA-IgG, VCA-IgM and EBNA-IgG antibody levels did not increase during observations of all rabbits (data not shown).

\section{$m R N A$ Expression of EBV-Related Genes in PBMCs from the Rabbits}

The mRNA expression of BMRF-1 (EA), EBNA-1, EBNA-2 and BZLF-1 in PBMCs from O-23, O-52, P-205 and $\mathrm{O}-122$ are summarized in table 2 and shown in figure 1A-2, B-2, C-2, D-2, respectively. BMRF-1 (EA) mRNA was detected in O-23 after day 70, whereas EBNA-1
mRNA was detected intermittently. BZLF-1 mRNA expression was observed on day 77. EBNA-2 mRNA was not detected throughout this study. BMRF-1 (EA) mRNA was transiently detected in O-52 on day 49 and 56. EBNA-1 mRNA was detected intermittently after day 21 . However, EBNA-2 and BZLF-1 mRNAs were not detected. BMRF-1 (EA), EBNA-1, EBNA-2 and BZLF-1 mRNAs were not detected in $\mathrm{O}-122$ and $\mathrm{P}-205$.

\section{Pathological Findings in the Rabbits}

O-23 was euthanized and dissected on day 77. No macroscopic pathological abnormalities were found in the secondary lymphoid tissues including the spleen, mesenteric lymph nodes, appendix, tonsils or liver by HE staining (fig. 2A-1, B-1, B-3, C-1). However, EBER-1-positive lymphocytes were detected by ISH in the spleen, mesenteric lymph nodes, appendix, tonsil and liver. In particular, they were accumulated in the mantle zone (fig. 2B-2, upper middle) and germinal center (GC; fig. 2B-2, lower right and lower middle) of some follicles in the appendix. A small number were found between the follicles. We also demonstrated the presence of an EBER1-positive lymphocyte in the squamous cell layer of the tonsils in this rabbit (fig. 2A-2). EBER-1-positive lympho- 


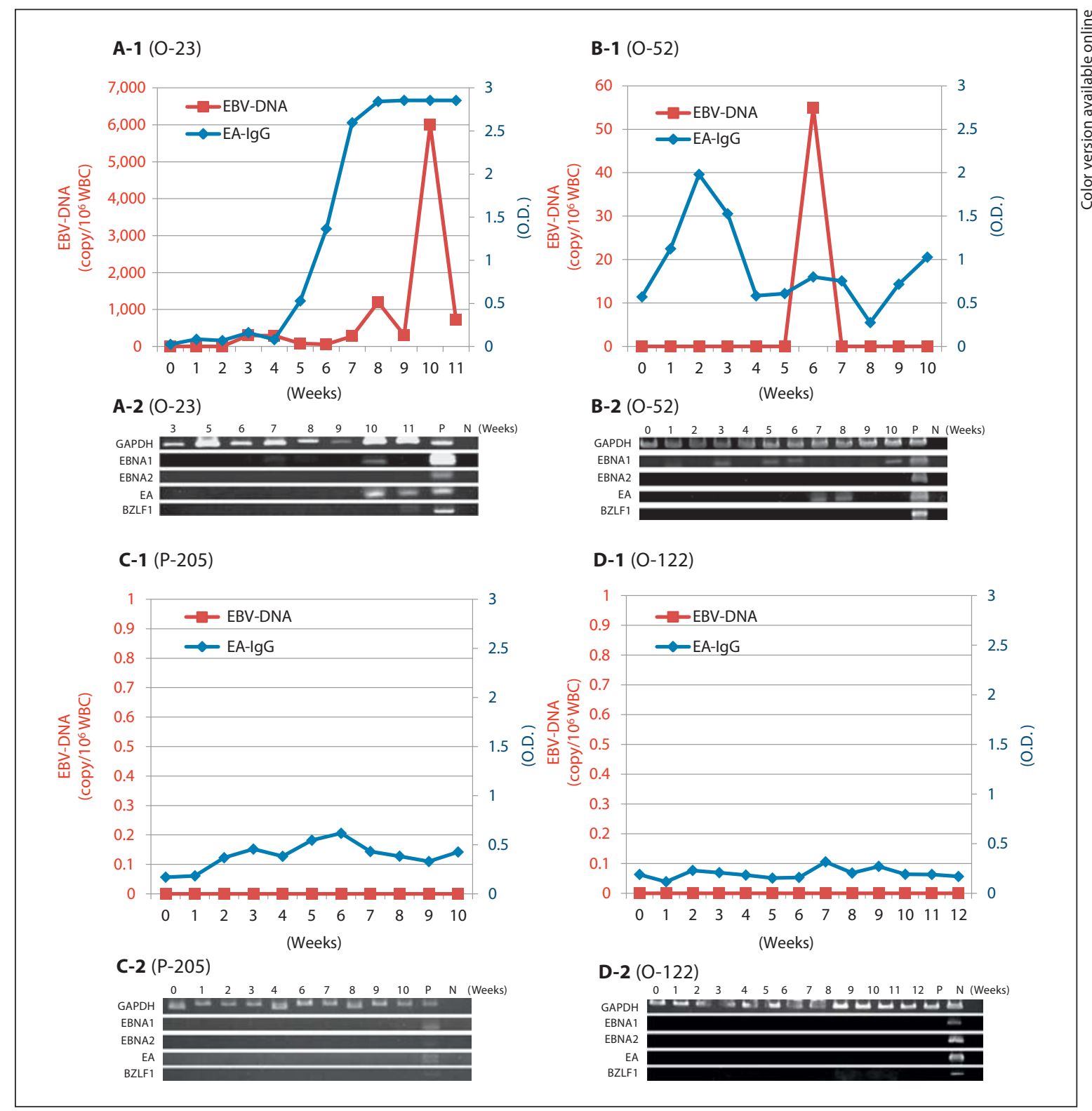

Fig. 1. Time course data for peripheral blood in terms of EBV-DNA and anti-EA-IgG antibody levels (A-1-D-1) and the mRNA expression of EBV-related genes [EBNA-1, EBNA-2, BMRF-1 (EA) and $B Z L F 1]$ as detected by RT-PCR (A-2-D-2). A O-23: type a infection. EBV-DNA was continuously detected in PBMCs from day 21. On day 70, a maximum $6.0 \times 10^{3}$ copies $/ 10^{6} \mathrm{WBCs}$ were detected. Simultaneously, EBNA-1, BMRF-1 (EA) and BZLF1 mRNAs were detected by RT-PCR. The EA-IgG levels increased sharply from day

cytes infiltrated only slightly into other secondary lymphoid tissues. P-203, P-205 and P-208 were euthanized and dissected on day 70 . We confirmed that there were no abnormal pathological findings, although few scattered EBER-1-positive lymphocytes were observed in the
35 to 49. High EA-IgG levels were maintained subsequently. B O-52: type $\mathrm{b}$ infection. EBV-DNA was detected transiently in PBMCs on day 42 , while BMRF-1 (EA)-mRNA was also detected. EBNA1-mRNA was detected intermittently after day 21 . The EA-IgG levels increased transiently on day 14. C P-205: type c infection. EBVDNA, EA-IgG and EBV-related gene expression were not detected in this type. D O-122: type d infection. EBV-DNA, EA-IgG and EBV-related gene expression were not detected in this type. 


\section{Discussion}

In this study, we inoculated P3HR-1-EBV into 12 Japanese White rabbits via the intranasal or intravenous routes. We diagnosed infection as the detection of EBVDNA in PBMCs or EBER-1-positive lymphocytes in tissues after inoculation. The inoculated rabbits were classified into the following four groups based on the data obtained: type a, EBV-DNA-positive in PBMCs and EBER-1-positive in tissue lymphocytes; type b, EBVDNA-positive in PBMCs but no EBER-1-positive in tissue lymphocytes; type c, EBV-DNA-negative in PBMCs but EBER-1-positive in tissue lymphocytes, and type d, EBVDNA-negative in PBMCs and no EBER-1-positive in tissue lymphocytes.

Only 1 rabbit $(\mathrm{O}-23)$ had a type a infection. For the first time, we showed the presence of an EBER-1-positive lymphocyte in the squamous cell layer of the tonsils in rabbit O-23 (fig. 2A-2, arrow) during our rabbit infection experiment series $[14,15]$. These EBV-infected lymphocytes may produce free virions that could infect other nearby uninfected lymphocytes and then they may be shed into the saliva, leading to the infection of new hosts. Most EBER-1-positive lymphocytes were observed in GCs and/or the mantle zones in some of the follicles in the appendix, while a small number of EBER-1-positive lymphocytes occasionally infiltrated other lymphoid tissues. This may be because the appendix is one of the most immunologically important organs in rabbits [25]. There are other models for the establishment of EBV latency in B cells. In one model $[26,27]$, EBV initially infects naïve $\mathrm{B}$ cells and induces cellular proliferation via the expression of the viral latency III genes immediately after infection. EBV-infected B cells then participate in GC reaction. After differentiation, memory $\mathrm{B}$ cells emerge as the sites of latent infection (latency 0). In another model [28], GC and/or memory B cells are directly infected with EBV, which expand without the GC reaction in patients with infectious mononucleosis. Based on our in vivo study using P3HR-1-EBV, we suggest that EBV-infected naïve B cells might not be capable of expanding immediately after infection to drive their proliferation because of their incapacity for expressing EBNA-2. Therefore, we considered that P3HR-1-EBV-infected lymphocyte populations might fail to expand unless they experience the GC reaction. We detected EBV-infected lymphocytes in GCs (fig. 2B-2, upper middle and lower right) and the mantle zones of a small number of follicles (fig. 2B-2, upper middle); therefore, EBV may directly infect GC B cells and/or naïve B cells, and the infected cells may undergo the GC
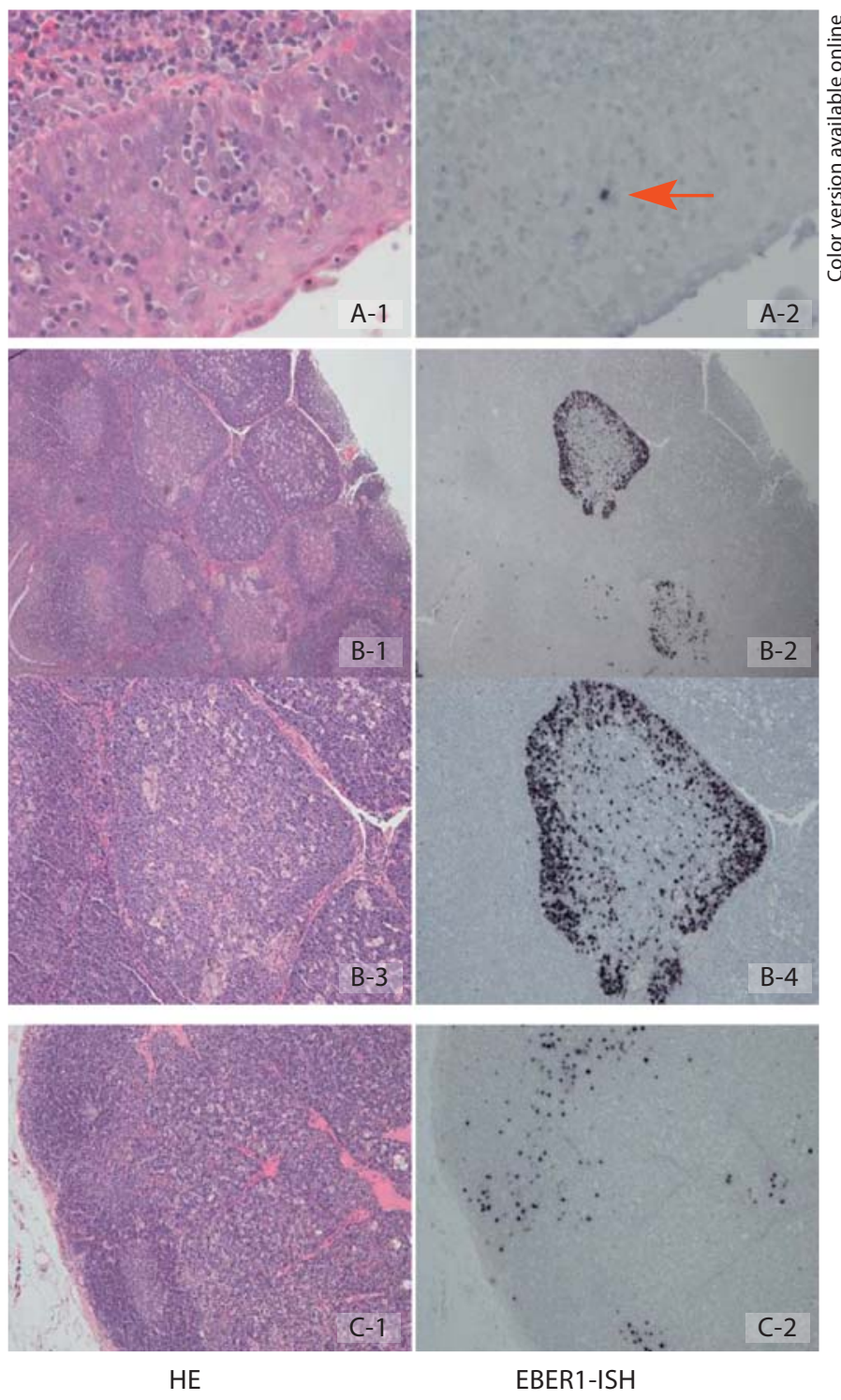

Fig. 2. Histopathological analysis and EBER-1-ISH of O-23. A Tonsil: no abnormalities were found in HE-stained specimens (A-1); ISH showed that an EBER-1-positive lymphocyte infiltrated the squamous cell layer (A-2, arrow). B Appendix: no abnormalities were found in specimens stained with HE (B-1, B-3); a number of lymphocytes expressed EBER-1 in some follicles (B-2); in particular, they accumulated in the mantle zone (B-2, upper middle) and germinal center (B-2, lower right). A magnified image of a follicle where EBER-1-positive lymphocytes are assembled is shown in B-3 (HE) and B-4 (EBER-1-ISH). C Mesenteric lymph node: no abnormalities were observed in HE-stained specimens (C-1); however, several scattered EBER-1-positive lymphocytes were found mainly in the parafollicular area of lymph nodes (C-2). 
reaction to gain access to the memory B cell pool, which is the main reservoir of EBV in the mantle zone.

Only 1 rabbit (O-52) had a type b infection. EBV-DNA, EBNA-1-mRNA and EA-IgG antibody were transiently detected in this specimen (fig. 1B-1, B-2). Thus, it is possible that a transient EBV infection was established. However, EBER-1-positive lymphocytes were not observed in any tissues after the autopsy. EBV may have been eliminated in this rabbit via innate and adaptive immunity mechanisms.

Three rabbits (P-203, P-205 and P-208) had a type c infection. A very small number of EBER-1-positive lymphocytes were occasionally detected in the secondary lymphoid tissues. This type was not observed in our previous studies $[14,15]$. It is likely that P3HR-1-EBV could not expand to produce detectable EBV-DNA levels in PBMCs, whereas B95-8-EBV could rapidly expand after inoculation via the expression of latent or lytic viral genes $[14,15]$. It is possible that the very small number of EBER1-positive lymphocytes observed in these rabbits may have been detected by chance and that they may be eliminated by innate immunity mechanisms during the rabbit's lifetime.

Seven rabbits (O-122, O-123, O-124, O-125, O-206, $\mathrm{O}-207$ and $\mathrm{P}-207)$ had a type $\mathrm{d}$ infection. These rabbits were not infected by P3HR-1-EBV.

We compared P3HR-1-EBV with B95-8-EBV $[14,15]$ in terms of EBV-DNA detection in PBMCs from inoculated rabbits (table 3). EBV-DNA detection in PBMCs was useful for understanding the status of EBV infection in surviving rabbits. During the observation period, EBVDNA was detected continuously in the peripheral blood of only 1 rabbit (O-23). It was difficult to detect EBVDNA in PBMCs from P3HR-1-EBV-inoculated rabbits, and even if they were infected, the first EBV-DNA detection in PBMCs from O-23 and O-52 was at 3 and 6 weeks, respectively, after inoculation. In contrast, EBV-DNA first appeared in the blood within 2 weeks of inoculation, and it was continuously detected for a prolonged period in rabbits that were efficiently infected with B95-8-EBV (table 3) $[14,15]$. One possible reason why the rabbits inoculated with P3HR-1-EBV were inefficiently infected is that P3HR-1-EBV has a deletion of EBNA-2. Therefore, we speculated that the growth capacity of lymphocytes infected with P3HR-1-EBV was inferior to that of lymphocytes infected with B95-8-EBV. Thus, even if some EBER-1-positive lymphocytes had remained latent in tissues, they might not have expanded into the blood to levels that were detectable by real-time PCR of EBV-DNA. In contrast, latent and/or lytic infection patterns of EBV-
Table 3. Comparison of EBV infection efficiency in rabbits between P3HR-1 and B95-8 EBV

\begin{tabular}{llll}
\hline $\begin{array}{lll}\text { Inoculation } \\
\text { route }\end{array}$ & $\begin{array}{l}\text { EBV-DNA detection } \\
\text { in PBMCs }\end{array}$ & $\begin{array}{l}\text { P3HR-1 } \\
(\mathrm{n}=12)\end{array}$ & $\begin{array}{l}\mathrm{B} 95-8^{1} \\
(\mathrm{n}=11)\end{array}$ \\
\hline Intravenous & positive (continuously) & 0 & 3 \\
& positive (transiently) & 0 & 3 \\
\multirow{4}{*}{ Intranasal } & negative & 4 & 1 \\
& positive (continuously) & 1 & 1 \\
& positive (transiently) & 1 & 3 \\
& negative & 6 & 0 \\
\hline & positive & $2 / 12(17 \%)$ & $10 / 11(91 \%)$ \\
\hline
\end{tabular}

${ }^{1}$ These data were previously described in the reports by Takashima et al. [14] and Okuno et al. [15].

related gene mRNA expression were observed in PBMCs from rabbits inoculated with both P3HR-1 and B95-8EBV $[14,15]$. This suggests that EBNA-2-deleted EBV can infect rabbits to induce lytic infection without EBNA-2 expression. EBNA-2-deleted P3HR-1-EBV is believed to infect lymphocytes in vitro, although it has no capacity for transforming B cells in vitro [19]. In fact, our unpublished data of succeeding the transformation of rabbit lymphocytes in vitro with B95-8-EBV but not with P3HR1-EBV will also reinforce the above-mentioned idea that EBNA-2 is essential for the transformation of B lymphocytes. In contrast, this rabbit in vivo model demonstrated that EBNA-2 may not be essential for in vivo EBV infection and P3HR-1-EBV can expand in vivo, occasionally.

These data suggest that P3HR-1-EBV is difficult to develop as an EBV-infected animal model, because 10 out of 12 rabbits inoculated with P3HR-1-EBV produced no detectable EBV-DNA in PBMCs. In our previous studies, B95-8-EBV-inoculated rabbits had higher infection efficiency and they were better than P3HR-1-EBV-inoculated rabbits as EBV-infected animal models. However, P3HR-1-EBV-inoculated rabbit models are still significant and useful for studying the characteristics of in vivo infection by type 2 EBV with EBNA-2 deletion.

\section{Acknowledgments}

The authors are grateful to the staff of the Division of Laboratory Animal Science, Research Center for Bioscience and Technology, Tottori University, for skillful technical assistance. We would also like to thank Enago (www.enago.jp) for their English language review. 


\section{References}

$>1$ Epstein MA, Achong BG, Barr YM: Virus particles in cultured lymphoblasts from Burkitt's lymphoma. Lancet 1964;1:702-703.

$\checkmark 2$ Cohen JI: Epstein-Barr virus infection. N Engl J Med 2000;343:481-492.

$\checkmark 3$ Hant DW: Classification of Epstein-Barr associated posttransplant lymphoproliferative disease: implications for understanding their pathogenesis and developing rational treatment strategies. Annu Rev Med 1995; 46:381-394.

$\checkmark 4$ Shope T, Dechairo D, Miller G: Malignant lymphoma in cottontop marmosets after inoculation with Epstein-Barr virus. Proc Matl Acad Sci 1973;70:2487-2491.

$\checkmark 5$ Epstein MA, zur Hausen H, Ball G, Rabin H: Pilot experiments with EB virus in owl monkeys (Aotus trivirgatus). III. Serological and biochemical findings in an animal with reticuloproliferative disease. Int J Cancer 1975; 15:17-22.

-6 Johannessen I, Crawford DH: In vivo models for Epstein-Barr virus (EBV)-associated B cell lymphoproliferative disease (BLPD). Rev Med Virol 1999;9:263-277.

7 Mosier DE, Gulizia RJ, Baird SM, Wilson DB: Transfer of a functional human immune system to mice with severe combined immunodeficiency. Nature 1988;335:256-259.

$>8$ Melkus MW, Estes JD, Padgett-Thomas A, Gatlin J, Denton PW, Othieno FA, Wege AK, Haase AT, Garcia JV: Humanized mice mount specific adaptive and innate immune responses to EBV and TSST-1. Nat Med 2006; 12:1316-1322.

9 Cocco M, Bellan C, Tussiwand R, Corti D, Traggiai E, Lazzi S, Mannucci S, Bronz L, Palummo N, Ginanneschi C, Tosi P, Lanzavecchia A, Manz MG, Leoncini L: CD34 ${ }^{+}$ cord blood cell-transplanted Rag2 $2^{-/-} \gamma_{c}^{-1-}$ mice as a model for Epstein-Barr virus infection. Am J Pathol 2008;173:1369-1378.

10 Yajima M, Imadome K, Nakagawa A, Watanabe S, Terashima K, Nakamura $H$, Ito $M$, Shimizu N, Honda M, Yamamoto N, Fujiwara S: A new humanized mouse model of EpsteinBarr virus infection that reproduces persistent infection, lymphoproliferative disorder, and cell-mediated and humoral immune responses. J Infect Dis 2008;198:673-682.
11 Hayashi K, Ohara N, Teramoto N, Onoda S, Chen HL, Oka T, Kondo E, Yoshino T, Takahashi K, Yates J, Akagi T: An animal model for human EBV-associated hemophagocytic syndrome: herpesvirus papio frequently induces fatal lymphoproliferative disorders with hemophagocytic syndrome in rabbits. Am J Pathol 2001;158:1533-1542.

12 Hayashi K, Jin Z, Onoda S, Joko H, Teramoto N, Ohara N, Oda W, Tanaka T, Liu YX, Koirala TR, Oka T, Kondo E, Yoshino T, Takahashi K, Akagi T: Rabbit model for human EBV-associated hemophagocytic syndrome (HPS): sequential autopsy analysis and characterization of IL-2-dependent cell lines established from herpesvirus papio-induced fatal rabbit lymphoproliferative diseases with HPS. Am J Pathol 2003;162:1721-1736.

13 Hayashi K, Joko H, Koirala TR, Onoda S, Jin ZS, Munemasa M, Ohara N, Oda W, Tanaka T, Oka T, Kondo E, Yoshino T, Takahashi K, Yamada M, Akagi T: Therapeutic trials for a rabbit model of EBV-associated hemophagocytic syndrome (HPS): effects of vidarabine or CHOP, and development of Herpesvirus papio (HVP)-negative lymphomas surrounded by HVP-infected lymphoproliferative disease. Histol Histopathol 2003;18: 1155-1168.

14 Takashima K, Ohashi M, Kitamura Y, Ando K, Nagashima K, Sugihara H, Okuno K, Sairenji T, Hayashi K: A new animal model for primary and persistent Epstein-Barr virus infection: human EBV-infected rabbit characteristics determined using sequential imaging and pathological analysis. J Med Virol 2008;80:455-466.

15 Okuno K, Takashima K, Kanai K, Ohashi M, Hyuga R, Sugihara H, Kuwamoto S, Kato M, Sano H, Sairenji T, Kanzaki S, Hayashi K: Epstein-Barr virus can infect rabbits by the intranasal or peroral route: an animal model for natural primary EBV infection in humans. J Med Virol 2010;82:977-986.

16 Kanai K, Takashima K, Okuno K, Kato K, Sano H, Kuwamoto S, Higaki H, Nagata K, Sugihara H, Kato M, Murakami I, Hayashi $\mathrm{K}$ : Lifelong persistent EBV infection of rabbits with EBER-1-positive lymphocyte infiltration and mild sublethal hemophagocytosis. Virus Res 2010;153:172-178.

$\checkmark 17$ Jeang KT, Hayward SD: Organization of the Epstein-Barr virus DNA molecule. III. Location of the P3HR-1 deletion junction and characterization of the NotI repeat units that form part of the template for an abundant 12-O-tetradecanoylphorbol-13-acetate-induced mRNA transcript. J Virol 1983;48: $135-148$.
18 Biggin M, Bodescot M, Perricaudet M, Farrell P: Epstein-Barr virus gene expression in P3HR1-superinfected Raji cells. J Virol 1987; 61:3120-3132.

19 Rabson M, Gradoville L, Heston L, Miller G: Non-immortalizing P3J-HR-1 Epstein-Barr virus: a deletion mutant of its transforming parent, Jijoye. J Virol 1982;44:834-844.

20 Harada S, Kieff E: Epstein-Barr virus nuclear protein LP stimulates EBNA-2 acidic domain-mediated transcriptional activation. J Virol 1997;71:6611-6618.

21 Baer R, Bankier AT, Biggin MD, Deininger PL, Farrell PJ, Gibson TJ, Hatfull G, Hudson GS, Satchwell SC, Séguin C, Tuffnell PS, Barrell BG: DNA sequence and expression of the B95-8 Epstein-Barr virus genome. Nature 1984;310:207-211.

-22 Kimura H, Morita M, Yabuta Y, Kuzushima K, Kato K, Kojima S, Matsuyama T, Morishima T: Quantitative analysis of Epstein-Barr virus load by using a real-time PCR assay. J Clin Microbiol 1999;37:132-136.

23 Bergallo M, Costa C, Baro S, Musso T, Balbo L, Merlino C, Cavallo R: Multiplex-nested RT-PCR to evaluate latent and lytic Epstein Barr virus gene expression. J Biotechnol 2007;128:462-476.

24 Chang KL, Chen YY, Shibata D, Weiss LM: Description of an in situ hybridization methodology for detection of Epstein-Barr virus RNA in paraffin-embedded tissues, with a survey of normal and neoplastic tissues. Diagn Mol Pathol 1992;1:246-255.

25 Hanson NB, Lanning DK: Microbial induction of $\mathrm{B}$ and $\mathrm{T}$ cell areas in rabbit appendix. Dev Comp Immunol 2008;32:980-991.

26 Babcock GJ, Hochberg D, Thorley-Lawson AD: The expression pattern of Epstein-Barr virus latent genes in vivo is dependent upon the differentiation stage of the infected $B$ cell. Immunity 2000;13:497-506.

27 Joseph AM, Babcock GJ, Thorley-Lawson DA: Cells expressing the Epstein-Barr virus growth program are present in and restricted to the naive B-cell subset of healthy tonsils. J Virol 2000;74:9964-9971.

28 Kurth J, Hansmann ML, Rajewsky K, Küppers R: Epstein-Barr virus-infected B cells expanding in germinal centers of infectious mononucleosis patients do not participate in the germinal center reaction. Proc Natl Acad Sci USA 2003;100:4730-4735. 